\title{
INHABILIDAD PARLAMENTARIA (TRIBUNAL CONSTITUCIONAL)
}

\author{
Comentario de Pablo Marshall Barberán
}

\author{
COMENTARIO DE JURISPRUdENCIA \\ Tribunal Constitucional de Chile, Rol 970-07
}

\section{i) Exposición de la sentencia}

El 7 de octubre de 2008, más de un año después de presentado el requerimiento, el Tribunal Constitucional resolvió la solicitud de inhabilidad del senador Alejandro Navarro, por haber participado en la marcha que realizara la Central Unitaria de Trabajadores el día 29 de agosto de 2007.

Las causales de inhabilidad que se le imputaran están establecidas en el artículo 60 consisten en:

[1] Ejerc[er] cualquier influencia ante las autoridades administrativas [...] en favor o representación [...] de los trabajadores en negociaciones o conflictos laborales, sean del sector público o privado, o que intervengan en ellos ante cualquiera de las partes (inc. 4 primera parte); y

[2] De palabra o por escrito incit[ar] a la alteración del orden público (inc. $5^{\circ}$ primera parte).

Respecto de la primera causal imputada, ella se configuraba según los requirentes, en la medida que el senador:

Encabezó una columna de trabajadores, ejerciendo influencia ante autoridades administrativas, como es Carabineros, invocando su calidad de senador, a favor de ellos, tratando de evitar que la Fuerza Pública cumpliera sus obligaciones constitucionales (c. 15).

El Tribunal desestimó que los hechos imputados constituyeran dicha causal, en la medida que no se logró identificar el conflicto laboral en el que el senador había intervenido (c. 17). Tampoco se puede tener, en la concepción del Tribunal, a Carabineros como la autoridad administrativa frente a la cual se ejerza influencia, dado que esta institución no participa en el conflicto laboral (cc. 18 y 21).

Respecto de la segunda causal imputada, esto es, de palabra o por escrito incitar a la alteración del orden público, los requirentes expusieron que ella era llevada a cabo por el senador, en cuanto: 
incitó a la alteración del orden público, tanto de las personas que se encontraban con él en la Plaza Italia como de los que, a través de la televisión, pudieron verlo participando en un acto ilegal, en circunstancias que el respeto al ordenamiento jurídico vigente integra la noción de orden público de nuestro país (c. 23).

El Tribunal, en esta ocasión, luego de una reflexión sobre el concepto de orden público (cc. 23-24), aclara que no es posible siquiera analizar si las acciones del senador constituyeron efectivamente una incitación a la alteración del orden público, pues dichas acciones no fueron probadas en la causa, como

consta en los oficios provenientes de la Presidenta de la República, de los Presidentes del Senado y de la Cámara de Diputados, del Ministerio del Interior, del Ministerio del Trabajo, de la Intendencia Metropolitana y de los Jueces del Trabajo de Santiago. En efecto, las autoridades mencionadas informan que sus actividades no se vieron alteradas y que no temieron por la seguridad de la Nación ni por el desarrollo de una "asonada del pueblo";

Que la restante prueba documental y confesional rendida no consigue alterar el mérito de lo razonado precedentemente, en especial la primera, que parcialmente se refiere a hechos, tanto distintos de los que sirven de base al requerimiento de autos, como de ocurrencia posterior al 29 de agosto de 2007. Las notas de prensa y grabaciones de televisión acompañadas dan cuenta de la adhesión del senador a la convocatoria de la CUT a la manifestación aludida, así como de su participación en la misma, sin que se acredite la incitación de palabra o por escrito a la alteración del orden público. Las declaraciones juradas acompañadas, por su parte, no hacen sino confirmar lo razonado precedentemente (cc. 27-28);

Existen dos cuestiones generales que cabe comentar en la labor realizada por el Tribunal en esta sentencia. La primera dice relación con la referencia tanto a las actas de la Comisión de Estudios de la Nueva Constitución y a la historia del establecimiento de la disposición (cc. 5-9 y 19). La segunda, dice relación con la prueba de los hechos que constituyen las causales imputadas (cc. 14-30).

\section{ii) Referencia a las actas}

El Tribunal en su argumentación hace referencia a las actas de la Comisión de Estudios de la Nueva Constitución para exponer los antecedentes de las disposiciones que se aplicarán (cc. 5-6). Luego hace referencia a las mismas actas para ilustrar el significado del término "conflicto laboral” utilizado por el inciso $4^{\circ}$ del artículo 60 (c. 19).

Las referencias a las actas son completamente innecesarias. Son utilizadas por el Tribunal como elementos ornamentales en el primer caso y como un recurso indirecto al diccionario de la Real Academia de la Lengua en el segundo. En la medida que la referencia a la historia fidedigna no parece ser útil para establecer el sentido que los miembros de la Comisión de Estudios en cuanto teóricos y dogmáticos otorgan a las 
disposiciones constitucionales. En la medida que las referencias están hechas sólo a la autoridad del legislador constituyente, como parece suceder aquí, su utilización resulta impertinente: (i) porque está haciendo referencia a una historia fidedigna incompleta (las actas están incompletas y faltan las actas de la Junta de Gobierno); y (ii) porque se sugiere que la idea de que una interpretación original, en el sentido de referencia a la conciencia del sujeto titular de la potestad constituyente al momento de ejercer dicha potestad, es legítima, lo que teniendo en cuenta el origen de la Constitución es aún más improbable.

\section{iii) Prueba}

Llaman la atención las pruebas que el Tribunal consideró para determinar la ocurrencia de los hechos constitutivos de las causales imputadas al senador Navarro. Entre las personas a las que se les tomó declaración aparecen el Presidente de la República, el Presidente del Senado, el Presidente de la Cámara de Diputados, el Presidente de la Corte Suprema, el Ministro del Trabajo, el Presidente del Tribunal Calificador de Elecciones y los jueces letrados del trabajo de Santiago. ¿Esas autoridades fueron testigos de los hechos? No parece pertinente la consideración de sus declaraciones. Sí podrían haber sido pertinentes testigos presenciales de los hechos, en particular funcionarios de Carabineros de Chile.

Por otro lado, es cuestionable la necesidad de pruebas en este asunto en la medida que los hechos que se le imputaron al senador fueron de público conocimiento. El que el Tribunal haga una exposición de las declaraciones tan poco atingentes para justificar que los hechos no resultan probados en vez de dirigirse directamente a la calificación de los hechos por todos conocidos, resulta, al menos, innecesaria.

\section{iv) Apreciación crítica de la causal del inciso 4 del artículo 60 de la Constitución}

Parece adecuado este lugar para formular una apreciación crítica respecto de la causal del inciso 4 considerada por el Tribunal Constitucional en esta sentencia.

La Constitución Política, tal como fue concebida por la Comisión de Estudios y la Junta de Gobierno, perseguía constituir un marco regulatorio que trabara la política democrática. La idea de democracia protegida encarna esa función. En ese escenario se establecieron una serie de disposiciones que pretendían darle a la política democrática un ámbito restringido de acción dentro de las funciones sociales y estatales. Así, se establecieron numerosas cortapisas para que los representantes del pueblo fueran los que, en última instancia, tomaran las decisiones políticas. El Consejo de Seguridad Nacional, los senadores designados y el Tribunal Constitucional fueron los mecanismos más llamativos para lograr dicho objetivo. Pero, por otro lado, se limitó también materialmente el ámbito de acción de los funcionarios políticos y de sus decisiones. Quizás basado en el principio de subsidiariedad, en su versión neoliberal, se impidió la intervención del Estado y sus magistrados en ámbitos que la Constitución entregaba a las asociaciones corporativas, esto es, a los gremios, sindicatos y asociaciones estudiantiles. 
La concepción del gobierno de la sociedad que los ideólogos de la Constitución tuvieron en cuenta a la hora de redactar sus disposiciones da cuenta de una profunda desconfianza hacia la democracia e indirectamente hacia la igualdad y la libertad de los ciudadanos. Por otro lado, consideraba necesario distribuir los ámbitos de la vida social, apartando de la política la vida estudiantil y laboral. La sentencia sostiene esto, al señalar:

[...] el deseo de deslindar la actividad parlamentaria de otros afanes sociales y económicos y por cierto políticos, considerado en ese momento de nuestra historia como ajenos a ella y excluyentes para sus ejecutores [...] (c. 10).

La política abarca todas las actividades y los ámbitos de la vida pública de un Estado. Extirpar la política de las relaciones laborales y estudiantiles no sólo no es necesario ni deseable, sino que es imposible. Lo que se hace mediante este tipo de disposiciones es inmunizar a ciertas asociaciones respecto de la acción estatal y, en ese sentido, asegurarles el monopolio de la acción política en determinados ámbitos de la vida social.

Las reformas a la Constitución no han afectado lo que parece ser uno de los aspectos de la idea de la democracia protegida. Ello puede deberse a que estas disposiciones no han tenido demasiada importancia en la práctica constitucional. Sin embargo, la desconfianza con la política democrática no puede continuar siendo un principio constitucional. Ello atenta contra los principios de justicia política más básicos, también contenidos en la Constitución.

La correcta interpretación de la Constitución no permite desatender el sentido normativo evidente de una disposición vigente. Con toda la fuerza del principio democrático, no puede establecerse más que una necesidad de interpretación restringida de la causal de inhabilidad de la que se trata el asunto que se comenta. Así, se requiere interpretar la causal del inciso $4^{\circ}$ arriba trascrita, solamente como un abuso de su posición de magistrado estatal para favorecer ilícitamente a una de las partes del conflicto laboral, esto es, una falta grave a la probidad. Esta consideración puede reforzar la interpretación estricta de la causal que el Tribunal funda en el carácter su sancionatorio. 